\title{
Assessing Assistive Learning Technologies with Experimental Design
}

\author{
Gede Pramudya ${ }^{1}$ \\ Department of Intelligent Computing and Analytics \\ Universiti Teknikal Malaysia Melaka, Malacca, Malaysia
}

\author{
Aliza Che Amran ${ }^{2}$ \\ Department of Electrical Engineering Technology \\ Universiti Teknikal Malaysia Melaka, Malacca, Malaysia
}

\author{
Muhammad Suyanto ${ }^{3}$ \\ Magister Teknik Informatika \\ Universitas Amikom Yogyakarta, Yogyakarta, Indonesia
}

\author{
Siti Nur Azrreen Ruslan ${ }^{4}$ \\ Faculty of Information \& Communication Technology \\ Universiti Teknikal Malaysia Melaka, Malacca, Malaysia \\ Helmi Adly Mohd Noor ${ }^{5}$ \\ Malaysian Institute of Industrial Technology \\ Universiti Kuala Lumpur, Kuala Lumpur, Malaysia \\ Zuraida Abal $\mathrm{Abas}^{6}$ \\ Department of Intelligent Computing and Analytics \\ Universiti Teknikal Malaysia Melaka, Malacca, Malaysia
}

\begin{abstract}
Assistive learning technologies are generally computer-based instruments which are focused at supporting individuals with disabilities in enhancing their learning session with minimal intervention of parents, guardians, as well as helpers. Assessments using experimental research design have frequently been utilized in order to evaluate their efficacy along with feasibility. An experimental design is categorized by experimental units or treatment to use, the tendencies that are tested, as well as the way treatments are designated to units. The experimental or treatment units need sufficient a number of and representative respondents or sample. Even so, due to the limited numbers of sample units or respondents, such type of experiments is noted as subtle yet challenging experiences. Based upon our substantial encounters, this article tries to disclose such precious research experiences.
\end{abstract}

Keywords-Assistive learning technology; disabilities; experimental design; mathematical learning; serious games; autism; visual perception

\section{INTRODUCTION}

Assistive Technologies (AT) are generally known as items, product systems or pieces of equipment, regardless if acquired commercially, altered, or tailored, which was utilized to improve, sustain, and also enhance functional skills of people with ailments [1]. Assistive learning technologies consist of computer-based instruments which are targeted to support individuals with disabilities in enhancing their learning with minimal intervention of guardians [2]. Additional investigation from the equivalent reference discovered that around 80 percent of released reports on AT executed to analyze the efficiency of the employment of AT in influencing respondents' capabilities and almost $50 \%$ of these studies utilized experimental design [3].

Implementing experimental design for the assessments of AT efficacy is exclusive, fragile and challenging experiences [4-6]. Participants of the studies are individuals or youngsters with disabilities, for instance partially strokes or with Autism
Spectrum Disorder (ASD). Moreover, there were various issues associated with attaining access, parent or guardian concern or approval, legal issues, along with reporting the discoveries [78] which affect the experiment's scope, paradigm, as well as the experiment data analysis.

In the subsequent Sections 2 and 3 of the article, the evaluations on experiences are pursued according to two chosen trials, which are a mathematics tutor, known as MathTutor, as well as a serious game diagnosis, known as ViPer Games, for children with autism. For each trial, the experimental design and setting used are explained. Besides that, the results gained from each trial are discussed. Next, Section 4 concludes this article and describes the recommendation for future research.

\section{MATHTUTOR TRIAL}

\section{A. Design and Setting}

This study focused primarily to evaluate the effectiveness of a Computer-Assisted Instruction (CAI) or tutor in assisting students with autism to master basic ideas of addition concept. In order to get the finest outcome from the trial, pre-test and post-test design of experiment was intended for the population of Malaysia resident, youngster with autism.

In order to do the experiment, a consent was requested from associated authorization bodies to access the facilities of guardians or schools. Even so, the consent could not be obtained for several months up to the point the population were switched to the youngster with autism in Melaka. Furthermore, during the stage of choosing respondents, basic data concerning the potential respondents were gathered by conducting pre-interviews with the educators.

Afterwards, validates if they possess the desired abilities for the experiment done by an observation. The respondents were needed to possess specified precondition abilities for instance to be able to comply with instructions orally or 
written, being capable of understanding numbers between 1 and 10, knowing how to work with laptops and mouse, and also being able to give attention to the activity no less than 10 minutes.

Next, 40 (forty) students diagnosed with autism who acquiring the desired abilities were chosen as respondents for the experiment at the end of the observation phase, by which they were separated into two different groups randomly; the control group that used teacher-assisted learning method, and the intervention group in which utilized the MathTutor. They were from a few primary schools in Ayer Keroh, Melaka.

Fig. 1 portrayed the design of the experiment. For this study, $O 1$ and $O 3$ signify the pre-test process employed to acquire data on respondent levels of addition concept on two separate groups whereas $\mathrm{O} 2$ and $\mathrm{O} 4$ are the post-test procedure. $P$ refers to the control group of the experiment which were employed the regular tutoring system through the entire experiment. In the other hand, $X$ is the intervention group which employed the MathTutor during the experiment.

Later, the study was conducted in an individual education class room. Throughout the experimental period, there was none other individual in the class room apart from the respondent and the researcher. Throughout the experimental session, the intervention modules which have been designed were displayed in the tutor using a laptop. Minimal guidance and prompt were present to the respondents whenever they were unable to comply with the verbal or written instructions.

\section{B. Results and Discussion}

This particular section reviews the overall achievement of respondents through the entire experiment. In order to measure the tutor's potency as a learning instrument, a pre-test and posttests had been performed within the experiment. Prior to starting the experiment, each of the respondents were instructed to take a pre-test as a way to identify their initial level of skill before treatment. To conclude, after the final session, the respondents were needed to take post-test, in which the questions were identical to the pre-test.

The control group of the experiment were employed the regular tutoring system through the entire experiment in which included 20 students with autism which were choose randomly. In order to evaluate if there is a substantial improvement amongst the pre-test and post-test results of the control group, the Wilcoxon Signed-Rank Test [9] was employed. In conclusion, the Wilcoxon Signed-Rank Test effectively identified the important different concerning the pre-test and post-test achievement within the control group $(Z=-3.91, p<$ $0.05)$. The outcome pointed out that a significant different did occurred for the control group achievement. To be exact, a significant variance was found between the pre-test and posttest scores in calculating the control group's skill level.

$$
\begin{array}{ccc}
O_{1} & P & O_{2} \\
O_{3} & X & O_{4}
\end{array}
$$

Fig. 1. Design of MathTutor Experiment.
In addition to that the distribution of pre-test and post-test scores of the respondents from the control group was reflected using scatter plots. The plot reveals $90 \%$ of the pre-test scores had been allocated under 50\% score. Thus, $90 \%$ from the respondents have scored equivalent to or lower than $50 \%$ score. Apart from that, this plot also demonstrates the post-test scores, highlights around 35\% from the respondents achieved over $60 \%$ score in which indicates approximately $60 \%$ from the respondents achieved high post-test scores (between $60 \%$ and $80 \%$ ). Thus, presenting enhancement before and after the experiment within the control group.

During the experimental case study, the intervention group included 20 students diagnosed with autism who were chosen randomly, by which the respondents experienced the tutor that determines the suitability of learning content according to the users' degree of proficiency through the entire experimental case study. Consequently, the Wilcoxon Signed-Rank evaluation was applied to evaluate if there is a substantial improvement amongst the pre-test along with post-test scores of the experiment group. In conclusion, the outcome discovered a substantial variance amongst the pre-test and post-test scores resulting from the experiment group $(Z=-3.92$, $\mathrm{p}<0.05)$. This outcome suggests that a significant different have occurred within the experiment group. Hence, an important variance was discovered amongst the pre-test and post-test scores in calculating the skill's level within the intervention group.

The experimental case study was performed to look for the significant variance between the control and intervention groups. Consequently, the post-test marks extracted from each group had been utilized to discover the outcomes of the experiment. Mann-Whitney U test has been utilized to correlate the skill's level amongst respondents within the experiment group, specifically exploring into their fundamental addition concept in mathematics at the end of the experimental case study, apart from ensuring the existence of an essential divergence involving the post-test scores extracted from the control as well as intervention groups. In addition, the discoveries of the Mann-Whitney $U$ test considering the purpose of figuring out the important difference between posttest scores of the control and intervention groups.

Additionally, it describes the fact that post-test rank average of the control group is 11.10 , whilst the intervention group is 29.92. Therefore, a massive variation of 18.82 points is reported amongst the rank averages of each group. According to the evaluation conducted, the figure of $(\mathrm{U}=$ $11.50, \mathrm{p}<0.05)$ attained signifies a rather notable variance involving the control along with intervention groups. Basically, the technique introduced to the intervention group verified to be more beneficial, compared to the method employed in the control group.

An informal observation has been executed on both experiment and control groups throughout the experiment. The observation was conducted whenever respondents attempted using the tutor. In addition, information was documented from the observations associated with their behaviour, development, and if they had needed assistance or guidance. 
Throughout the first session, all the respondents displayed some curiosity about utilizing the computer or laptop as a learning instrument to learn the addition skill even though few appeared playful and required assistance to remain concentrated at the beginning period of the session. Apart from that, a number of the respondents demanded assistance or guidance when reaching reinforcement exercises, particularly with questions that included numbers bigger than five.

Within the second session, several respondents demonstrated that they able to recall the lesson learned previously. Besides using the pictures presented with the questions, some of respondents counted using fingers. In spite of that, some respondents continue to repeat the same mistakes they did previously. Additionally, most of the respondents appeared interrupted by the audio from the answer button. Thus, throughout this period, several respondents required assistance and guidance, particularly when answering reinforcement exercises.

Afterwards, during the third session, the majority of the respondents demonstrated to be able to recall the lesson learned in previous session. Furthermore, majority respondents were able to concentrate on both learning as well as assessment during this session. However, some respondents had required guidance, and a few others needed both assistance as well as guidance during calculations. In fact, majority of the respondents likewise appeared to have fun with the learning period and asked to repeat the lesson.

In the meantime, in the fourth session, most of the respondents exhibited motivation and curiosity through the lesson, even though several happen to be diverted by the audio from the answer button. Throughout this session, almost all respondents only needed guidance whenever attempting the calculations. Additionally, they appeared to have fun with the session and wanted to repeat the session.

Next, in the fifth session, identical to the prior session, the majority of respondents demonstrated motivation and curiosity throughout the lesson, however a few ended up diverted by the audio from the answer button. As a result, those distracted had wanted assistance and direction while answering reinforcement question.

During the sixth and the last sessions, almost all respondent appeared wanting to begin the learning lesson. On top of that, the majority of respondents were capable to achieve the exercise efficiently, even though only several needed minimum guidance instructions throughout reinforcement exercise. The respondents also appeared to have fun with the learning period and wanted to repeat the session.

On top of that, throughout the experiment, the majority of the respondents shown enhancement in behaviour as they retained excellent behaviour throughout the entire remaining experimental learning session, compared to the initial two sessions. The respondents also demonstrated that they loved the learning period in which they asked to repeat the lesson and frequently asked to use the computer. Hence, the approach utilized in the tutor, for instance pictures, animated graphics, and also audio, appeared to catch the attention of these students with autism, other than maintaining their concentrate while learning took place. Consequently, the tutor had been proven to boost both involvement as well as curiosity among students with autism throughout the sessions. Additionally, all of the respondents actively took part throughout the learning session, in which they counted along with the tutor. Therefore, the respondents were intrigued to follow the learning sessions and wanted the lesson to be repeated. Apart from that, the tutorial along with the examples presented to them gained their interest, hence assisted them in memorizing the lesson learned [24].

\section{VI-PER GAMES TRIAL}

\section{A. Design and Setting}

Early recognition and examination to youngster with autism is necessary to expose these individuals with early intervention program in an effort to overcome, or to lessen at least, the difficulties relating to autism. This study aimed to build up serious games, named Vi-Per Games, as an instrument for special education teachers and guardians to examine visual perception difficulties in students with autism. The Chalfont diagnosis principle has been utilized for production of the instrument [10]. In an effort to accomplish exterior validity of the model of experimental research, a trial was developed for the population of students or youngsters diagnosed autism in Johor. As above, attaining access was started from special classes or centres of therapy of youngsters or students with autism. Despite the fact that the access was given within the long-term excess limit, yet there are merely a few respondents who were capable to be a part of the research due to the fact that only some of the guardians or parents return the concern forms. Eventually, only 10 (ten) students are keen to be the research respondents.

This research employed the mixed approach, applying both quantitative as well as qualitative approaches. The application of qualitative technique employed in this study is to verify the model as well as the perception of teachers in regards of the application of the serious games for diagnosing visual perception difficulties in students with autism. Alternatively, the quantitative technique is to verify the reliability of the serious games for examining and producing systematic and extensive analysis reports on visual perception difficulties in students with autism.

This section also addresses the features of research design, such as the tool employed in this research. ADDIE model is utilized as the research design to build up the visual perception diagnostic instrument. This five-phase systematic model, known as Analysis, Design, Development, Implementation and Evaluation, is employed to steer throughout the steps involved in developing multimedia products for all kinds of framework. Each phase offers a course of tasks that assist to ensure production initiatives remain on time, on track and on target. Finishing each stage sufficiently boosts the opportunity that the data displayed essentially continues to be relevant to the requirements of the investigation. Selection of the respondents can be viewed as a purposive sampling. In accordance with Bogdan \& Biklen [11] and Chaudary [12] since the respondents were recognized and chosen according to some purposive key points for instance accessibility, thus the selection of the respondents can be treated to be purposive 
sampling rather than random sampling. Additionally, precise information extracted from the respondents was best suited to the objective of the research.

The information was gathered with the contribution of special education school teachers as well as students diagnosed with autism of SMK Tun Syed Nasir Ismail and SMK Bandar Baru Uda, both are high schools located at Johor Bahru. The information associated with the gathering approaches employed in this evaluation is also analyzed and explained. Information regarding visual perception level of each respondent are ordinal type. They were assigned or coded an ordinal scale dimension. The Wilcoxon Signed-Rank test was utilized in each sample in verifying no substantial improvement between respondent conventional as well as $\mathrm{Vi}$ Per Games test outcomes. In the meantime, data that illustrate the respondent understanding, figure on utilizing the comment, prototype, and general associated results are nominal and/or ordinal type. To achieve the goal of data evaluation, descriptive statistics for instance percentiles, median, and percentage were used. Generally, this study consists of the emergences of the Vi-Per Games system for the diagnosis of visual perception for students with autism apart from how special education teachers employed these games in the classroom. Additionally, at the beginning stage, a diagnostic test was obtained by the respondents. Besides, this technique has also been identified for this research and explains the research design, research strategy, data collection, sampling strategy, along with the research data evaluation.

\section{B. Research Approach}

Main ideas of research domain require details knowledge about research technique. In accordance with Brewer et al. [13], quantitative research is known as hypothesis testing research whereby research start with statements of idea extracted from the research hypotheses. Furthermore, a qualitative research technique according to interviews, document reports, and observations extracted from real life is argued in order to fulfil the investigation goals. Nevertheless, several other research strategies were also be reviewed. From literary works and discussions on numerous traditions and strategies to "good" analysis [14-17], four prospective research techniques have been regarded for the study. There is quantitative experimental research, qualitative observational research, participatory action research as well as logical theoretical research. Two types of strategies were employed together with research techniques, which are qualitative technique with questionnaires and quantitative technique with experiment. The result was accumulated by utilizing the survey technique as well as using a questionnaire to obtain the views of the sample population. Malhotra [18] and Sekaran [19] reported that gathering information for a survey can be assisted by face-to-face sessions. In addition, observations, e-mails, telephone interviews, personally administered questionnaires or the Internet can help to accumulate the data required. Then, the Likert scale, a well-known approach to accumulating data regarding surveys was employed. This technique is utilized to determine behaviour. It needs respondents to give responses to a series of statements. According to Saunders et al. [20], the responses range from highly agreed to highly disagree. Thus, the Internet and personally administered approaches were regarded as the utmost relevant technique to acquire the information.

In this research, qualitative and quantitative techniques were chosen. The qualitative research employed in this research is to verify the model as well as the teachers' perception towards the implementation of the serious games in order to diagnose visual perception difficulties in autistic students. While the quantitative study utilized in this study is to verify the precision of the serious games for diagnosing visual perception issues in autistic students and produce extensive and organized analysis reviews of visual perception difficulties.

To illustrate how the prototype was applied, a separate sample pre-test and post-test accompanied by a case study design was used. The respondents were divided into independent sample sizes of 3, 3 and 4. Kerlinger [21] and Tuckman [22] explain one group pre-test and post-test preexperimental structure as shown in Fig. 2.

A measurement or observation is specified as $\mathrm{O}$ while a treatment or the occurrence of the treatment is specified as X. Each $\mathrm{O}$ has an arbitrary subscription to facilitate referral and recognition. In this research, to offer some details regarding the sample of respondents, measurement or observation $\mathrm{O} 1$ was completed by implementing pre-test or survey. Next, a treatment $\mathrm{X}$ was tested on the subjects. Lastly, an additional measurement or observation $\mathrm{O} 2$ was performed on the group members to access the consequences of treatment $\mathrm{X}$.

The one group pre-test and post-test was employed thrice in order to conquer the history bias that was the primary inherent insufficiency in this design [22]. The phrase history bias refers to the assumption produced by occurrence happen simultaneously in the environment when testing the experimental variable. Pramudya [23] revised design, in which recognized pre-test and post-test design of separate samples is highlighted in Fig. 3.

For this research, $O 1, O 3$, and $O 5$ consecutively signify the pre-test process employed to acquire data on respondent levels of visual perception analysis by implementing the standard approach by Ministry of Education Malaysia, Visual Perception Diagnostic Test Instrument on three separate samples. $X$ is the instructional treatment used for the Vi-Per Games prototype, and $02, O 4$ and $O 6$ are the post-test procedure. Questionnaires and information of student with autism statistics in the database were utilized to accumulate details of the level of visual perception of the respondent, the teacher opinion of the prototype, and additional general relevant feedback from the three samples after the treatment.

$$
\begin{array}{lll}
\mathrm{O}_{1} & \mathrm{X} & \mathrm{O}_{2}
\end{array}
$$

Fig. 2. Design of Vi-Per Games Experiment.

$\begin{array}{ccccc}O_{1} & X & O_{2} & & \\ & O_{3} & X & O_{4} & \\ & & O_{5} & X & O_{6}\end{array}$

Fig. 3. Separate-Sample. 


\section{Results and Discussion}

The outcomes of the three distinct samples reveal that there were no considerable dissimilarities in this research between the pre-test and also the post-test scores of respondents. It demonstrates that, within each sample groups, the respondent's pre and post-test scores were identical. As the collection of scores was conducted in three different distinct samples on distinct timelines, the history bias in this research was prevented. That is to say it is less likely that some other occasion would have happened concurrently in the three samples to impact the implement of the serious game setting. This sustains the final outcome that the evaluation scores generated by applying the serious games are precise. In which indicates that the serious game technique by utilizing Vi-Per Games as a substitute technique may gave advantages to the students with autism as well as teachers in the examination of the visual perception level of students with autism.

Since Vi-Per Games could enhance the diagnostic procedure, motivate students, and boost their curiosity as well as inspiration, these games can be adopted to aid students with autism to endure diagnostic testing. Evidently, these discoveries are coherent with a prior study, which likewise point out student with autism compatibility with games. Additionally, the discoveries also emphasize that games can assist to assess the performance of visual perception.

\section{CONCLUSION}

This article is supposed to examine encounters on implementing experimental design in two distinct scientific studies. The key purposes of the researches were to analyze the efficiency regarding two AT known as MathTutor as well as Vi-Per Games in aiding students with autism to acquire the elementary mathematics principles of addition and aiding guardians to analyze children with autism. Associate samples were developed to be able to fulfill the layout's external validity or to generalize the discoveries. Nevertheless, due to the restricted concern from the parents, guardians or guardians of the youngster along with minimal accessibility obtained, only small-scale samples or respondents are used. This pressured the researchers to modify the scope, paradigm, as well as the research data analysis. Therefore, more examples of experimental design setting for small number of samples from studies on using AT for children with disabilities may enrich knowledge and experiences in this field of experimental design.

\section{ACKNOWLEDGMENT}

The authors would like to acknowledge the Centre for Advanced Computing Technology (C-ACT), Fakulti Teknologi Maklumat Dan Komunikasi, Universiti Teknikal Malaysia Melaka for their support in the research.

\section{REFERENCES}

[1] A. G. D. Dell, A. Newton and J. G. Petrof, "Assistive Technology in the Classroom: Enhancing the School Experiences of Students with Disabilities,” Boston: Allyn \& Bacon, 2012.

[2] G. Alnahdi, "Assistive Technology in Special Education and the Universal Design for Learning," Turkish Online Journal of Educational Technology-TOJET, vol. 13, no. 3, pp. 18-23, April 2014.
[3] S. Alper and S. Raharinirina, "Assistive Technology for Individuals with Disabilities: A Review and Synthesis of the Literature," Journal of Special Education Technology, vol. 21, no. 2, pp. 47-64, 2006.

[4] E. B. Itzchak and D. A. Zachor, "Who benefits from early intervention in autism spectrum disorders?," Research in Autism Spectrum Disorders, vol. 5, no. 1, pp. 345-350, 2011.

[5] M. Tincani, J. Travers, and A. Boutot, "Race, Culture, and Autism Spectrum Disorder: Understanding the Role of Diversity in Successful Educational Interventions," Research and Practice for Persons with Severe Disabilities, vol. 34, no. 3-4, pp. 81-90, 2009.

[6] S. W. White, K. Keonig, and L. Scahill, "Social Skills Development in Children with Autism Spectrum Disorders: A Review of The Intervention Research," Journal of Autism and Development Disorders, vol. 37, pp. 1858-1868, 2007.

[7] W. C. Mann, "Effectiveness of Assistive Technology and Environmental Interventions in Maintaining Independence and Reducing Home Care Costs for the Frail Elderly: A Randomized Controlled Trial," Archives of Family Medicine, vol. 8, no. 3, pp. 210-217, 1999.

[8] B. Robins, K. Dautenhahn, R. Boekhorst, and A. Billard (Eds.). "Proceeding of the 2004: IEEE International Workshop on Robot and Human Interactive Communication," Proceeding of the 2004: IEEE International Workshop on Robot and Human Interactive Communication, 2004.

[9] L. Statistics, "Wilcoxon signed-rank test using SPSS statistics. Statistical tutorials and software guides". 2015.

[10] H. A. Noor, F. Shahbodin, G. Pramudya, N. C. Mohd, S. N. Razali, M. S. Khalid, R. Kassim, F. A. Rahman, and Z. Baharum, "A prototype development of visual perception diagnosis games for autism children," International Journal of Advanced and Applied Sciences, vol. 4, pp. 6872, 2007.

[11] R. C. Bogdan, and S. K. Biklen, Quantitative Research for Education: An Introduction to Theory and Methods. Boston: Allyn \& Bacon, 1992.

[12] C. M. Chaudary, Research Methodology. Jaipur: S.K. Parnami, 1991.

[13] R. Brewer, F. Biotti, C. Catmur, C. Press, F. Happé, R. Cook, and G. Bird, "Can Neurotypical Individuals Read Autistic Facial Expressions? Atypical Production of Emotional Facial Expressions in Autism Spectrum Disorders," Autism Research, vol. 9, no. 2, pp. 262-271, 2015.

[14] J. Corbin and A. Strauss, Basics of Qualitative Research : Techniques and Procedures for Developing Grounded Theory. Thousand Oaks,CA: SAGE, 2008.

[15] N. K. Denzin, and Y. S. Lincoln, The SAGE Handbook of Qualitative Research. California: SAGE, 2011.

[16] M. B. Miles, and A. M. Huberman, An Expanded Sourcebook: Qualitative Data Analysis. New York: SAGE, 1994.

[17] G. Walsham, "Interpretive Case Studies in IS Research: Nature and Method European,” Journal of Information Systems, vol. 15, pp. 220230, 1995.

[18] N. K. Malhotra, Marketing Research: An Applied Orientation. Singapore: Prentice Hall, 1999.

[19] U. Sekaran, Research Methods for Business: A Skill-Building Approach. New York: John Wiley \& Sons, 2003.

[20] M. N. K. Saunders, P. Lewis, and A. Thornhill, Research Methods for Business Students. Harlow: Pear-son, 2012.

[21] F. N. Kerlinger, Foundation of Behavioral Research. Florida: Harcourt Brace \& Co., 1992.

[22] B. W. Tuckman, Conducting Educational Research. Florida: Harcourt Brace \& Co., 1994.

[23] G. Pramudya, "Using an Adaptive Web-Based Learning Environment to Develop Conceptual and Procedural Knowledge," (Unpublished doctoral dissertation). University of Wollongong, Australia, 2004.

[24] G. Pramudya, and S. N. A. Ruslan, Proceedings of Mechanical Engineering Research Day 2017, 2017. 